\title{
Study of factors affecting the outcome of operative management of malleolar fractures
}

\author{
Venugopal S M ${ }^{1, *}$, G. Jagadesh ${ }^{2}$, Prasanna Maddiwar ${ }^{3}$, Karthik Gudaru ${ }^{4}$ \\ ${ }^{1,4}$ Assistant Professor, ${ }^{2} \mathrm{HOD},{ }^{3}$ Senior Resident, Dept. of Orthopaedics, Balaji Institute of Surgery Research, and Rehabilitation \\ for the Disabled (BIRRD) Hospital Tirupati, Andhra Pradesh, India
}

*Corresponding Author:

Email: shring31@gmail.com

\begin{abstract}
Introduction: One of the most common fractures an orthopaedic surgeon encounters is Malleolar fractures. As with all intra articular fractures accurate reduction and stable internal fixation of malleolar fractures is desirable. The present study aimed at analyzing the factors influencing the outcome of operative management of malleolar fractures.

Materials and Methods: In this prospective study 25 patients with Malleolar fractures who were surgically treated between 2014 to 2016 were included. All patients were treated in accordance with A.O. principles. Patients aged above 18 years, with unstable fractures were included in this study. Post op protocol was below knee POP cast with a dorsal window for ankle mobilization and non-weight bearing walking with walker for 4 weeks post operatively. Baird and Jackson ankle scoring system was used to analyze the results. The follow up period for all patients was 60 weeks.

Results: In this series of fixation of malleolar fractures with various techniques had Fair results in $84 \%$ and poor results in $16 \%$ as per Baird and Jackson Score. The average time to union was 12 weeks. The complications leading poor result were instability, Pain at rest, arthritic changes.

Conclusion: Open reduction and internal fixation guaranty high standard of reduction besides eliminating the chances of loss of reduction. In our study, the Extent of anatomical reduction achieved in the surgery and Post-operative ankle mobilization and patients' compliance influenced the outcome. Restoration of fibular length and rotation is critical in re-establishing a stable ankle mortise and perfect talar alignment. We conclude tension band wiring is the preferred method for small fracture fragments and osteoporotic bones of both medial and lateral malleolus.
\end{abstract}

Keywords: Malleolar fractures, Anatomical reduction, Baird and Jackson score.

\section{Introduction}

One of the most common fractures an orthopaedic surgeon encounters is Malleolar fractures. The annual incidence of ankle fracture is between 107 and 184 per 100,000 perssons. ${ }^{1-3}$ Ankle fractures usually affect young men and elderly females. ${ }^{4}$ As with all intra articular fractures accurate reduction and stable internal fixation of malleolar fractures is desirable. The results of inaccurately reduced malleolar fractures are post traumatic painful restriction of motion or osteoarthritis of ankle or both. The superiority of open reduction and internal fixation over closed treatment has been thoroughly demonstrated in literature. However all studies in operative treatment have not obtained good results in cases of malleolar fractures.

A rewarding outcome for the patient and surgeon which is a proper anatomical alignment and stability of ankle joint can be achieved only with open reduction and internal fixation technique for malleolar fractures.

The purpose of this study is to analyze the factors influencing the outcome of operative management of malleolar fractures.

\section{Materials and Methods}

In this prospective study twenty five patients with malleolar fractures of ankle presenting to Balaji Institute of Surgery Research, and Rehabilitation for the Disabled [BIRRD] Hospital, Tirupati, Andhra Pradesh from September 2014 To December 2016 were operated with open reduction and internal fixation by various methods. The ethical committee approval was acquired to conduct the study.. The inclusion criteria were patients with unstable malleolar fracture, skeletally matured, closed type, type I and type II compound fractures, acute fractures (seen within $72 \mathrm{hrs}$ of the injury).

Indications for surgery were fractures of the articular surface of the ankle, displacement greater than $2 \mathrm{~mm}$ at the lateral, medial malleolus, in the absence of medial malleolar fracture, widening of the medial clear space greater than $2 \mathrm{~mm}$, posterior malleolar fracture with $>2 \mathrm{~mm}$ displacement or fracture fragment $>25 \%$ of the tibial articular surface. Exclusion criteria were skeletally immature, compound fractures of type III A, $\mathrm{B}$ and $\mathrm{C}$, fractures associated with pilon or plafond fractures of tibia, previous ankle fracture, polytrauma, associated with bilateral lower limb fractures and any concomitant painful or disabling disease of lower limb that could interfere with evaluation of the affected ankle.

Out of 25 there were 16 males and 9 females, In 16 patients $(64 \%)$ right ankle was involved and in 9 patients $(36 \%)$ it was left ankle. Patients were aged between 18 to 65 with an average of $40.9 \mathrm{yrs}$. The majority were in the $4^{\text {th }}$ decade. 13 [52\%] patients presented to us with the history of Road Traffic Accidents, in 8 [32\%] patients fracture was due to slipping and tumbling. Fall from height was the cause 
of fracture in the rest 4 [16\%] patients. (Table 1) As per Lauge- Hansen's classification In 14 (56\%) patients sustained fracture due to supination external rotation, followed by pronation external rotation type in $6(24 \%)$ patients, supination adduction type in $4(16 \%)$ and only in $1(4 \%)$ patient sustained injury by pronator abduction type (Table 2). The majority of the fractures 16 [64\%] were of Bimalleolar type, followed by 8 [24\%] were Unimalleolar type. Three [12\%] patients sustained Trimalleolar fracture.

Detailed history pertaining to mode of injury, chronicity of the injury to the time of presentation was obtained at the time of admission and a detailed examination was done. Ankle trauma radiographs (i.e. anteroposterior, lateral and mortise view) were taken. After all investigations and after surgical fitness from anesthesiologist the cases were taken up for surgery.

Under spinal anesthesia and tourniquet, open reduction and internal fixation of the malleolar fracture were performed as per AO principles. Fibular fractures were fixed first. Fibula fractures were fixed with Dynamic compression plate(DCP) in $14(56 \%)$ cases, DCP with lag screw in 7 (28\%) cases, DC buttress plate, DCP with syndesmotic screw, tension band wiring and lag screw alone in one case each $(4 \%)$. Medial malleolar fractures were fixed with malleolar screw with $\mathrm{k}$ wire in $15(60 \%)$ patients, malleolar screw alone in $4(16 \%)$ patient, tension band wiring in $3(12 \%)$ patients and $3(12 \%)$ patients with Buttress plate. (Table $3 \& 4$ )

After suture removal on the $12^{\text {th }}$ post-operative day, a below knee POP cast with a dorsal window was applied, to facilitate passive dorsiflexion movement of the foot. Non Weight- bearing mobilization was allowed for 4 weeks. After 4 weeks, cast was discontinued and active range of motion was started with partial weight bearing.

Full weight bearing was allowed after 12 weeks. Regular follow ups of the patients were done for every six weeks, by assessing functional parameters and $\mathrm{x}$ rays in all three views, until bony union on $\mathrm{x}$-rays.

Table 1: Mode of injury

\begin{tabular}{|l|c|c|}
\hline Mode of injury & $\begin{array}{c}\text { Number } \\
\text { of } \\
\text { Patients }\end{array}$ & Percentage \\
\hline $\begin{array}{l}\text { Road traffic } \\
\text { accident }\end{array}$ & 13 & $52 \%$ \\
\hline Fall from height & 4 & $16 \%$ \\
\hline $\begin{array}{l}\text { Slipping and } \\
\text { tumbling }\end{array}$ & 8 & $32 \%$ \\
\hline
\end{tabular}

Table 2: Mechanism of injury

\begin{tabular}{|l|c|c|}
\hline $\begin{array}{l}\text { Lauge-Hansen } \\
\text { fracture classification } \\
\text { type }\end{array}$ & $\begin{array}{c}\text { Number } \\
\text { of } \\
\text { patients }\end{array}$ & Percentage \\
\hline Supination-adduction & 4 & $16 \%$ \\
\hline
\end{tabular}

\begin{tabular}{|l|c|c|}
\hline $\begin{array}{l}\text { Supination-external } \\
\text { rotation }\end{array}$ & 14 & $56 \%$ \\
\hline Pronation abduction & 1 & $4 \%$ \\
\hline $\begin{array}{l}\text { Pronation external } \\
\text { rotation }\end{array}$ & 6 & $24 \%$ \\
\hline Pronation dorsiflexion & 0 & $0 \%$ \\
\hline
\end{tabular}

Table 3: Implants used for medial malleolus

\begin{tabular}{|l|c|c|}
\hline Type of Implant & $\begin{array}{c}\text { Number } \\
\text { of } \\
\text { Patients }\end{array}$ & Percentage \\
\hline Malleolar screws & 4 & $16 \%$ \\
\hline $\begin{array}{l}\text { Malleolar screw + } \\
\text { K- Wire }\end{array}$ & 15 & $60 \%$ \\
\hline $\begin{array}{l}\text { Tension band } \\
\text { wiring }\end{array}$ & 3 & $12 \%$ \\
\hline Buttress plate & 3 & $12 \%$ \\
\hline
\end{tabular}

Table 4: Implants used for lateral malleolus

\begin{tabular}{|l|c|c|}
\hline Type of implant & $\begin{array}{c}\text { Number } \\
\text { of } \\
\text { patients }\end{array}$ & Percentage \\
\hline $\begin{array}{l}\text { Dynamic compression } \\
\text { plate }\end{array}$ & 14 & $56 \%$ \\
\hline $\begin{array}{l}\text { Lag screw + } \\
\text { Dynamic compression } \\
\text { plate }\end{array}$ & 7 & $28 \%$ \\
\hline DC Buttress plate & 1 & $4 \%$ \\
\hline $\begin{array}{l}\text { Syndesmotic screw + } \\
\text { Dynamic compression } \\
\text { screw }\end{array}$ & 1 & $4 \%$ \\
\hline Tension band wiring & 1 & $4 \%$ \\
\hline Lag screw alone & 1 & $4 \%$ \\
\hline
\end{tabular}

\section{Results}

All 25 patients were followed up for a period of 60 weeks. The duration between occurrence of the injury and internal fixation in fresh cases varied from 5 to 7 days and in late cases from 10 days to 15 days.

BAIRD and JACKSON ${ }^{5}$ ankle scoring system was used to analyze the results of functional and radiological outcome. The evaluation was based on a questionnaire and clinical, radiological examination. The range of plantar flexion and dorsiflexion was measured with the patient seated and the knee extended, using a Goniometer. The difference between injured and the uninjured side was recorded. Radiologically the medial clear space, superior joint space and talar tilt was measured. These scores were evaluated and noted for the each follow up of the patient; [each visit of being 6 weeks interval] up to $10^{\text {th }}$ visit.

In this study, 17 [68\%] patients had no pain and 2 [8\%] patients had mild pain after strenuous activity, 2 [8\%] patients complained pain on activity of daily living and 2 [8\%] had pain only on weight bearing on the affected side and only 2 [8\%] patients complained pain at rest at the time of final follow up. 
At the final follow-up, only one patient [4\%] had clinical instability, 14 [64\%] patients could walk desired distances without limp or pain; 6 [24\%] patients were able to walk desired distance with mild pain, 3 [12\%] had moderately restricted ability to walk, 2 [8\%] could walk only short distances and 1 [4\%] patient remained with inability to walk.

In our series, 16 [64\%] patients were able to do their usual occupation without any restrictions at their final follow up, 5 [20\%] had restrictions in certain strenuous activities, while $2[8 \%]$ could perform their usual occupation with substantial restriction, 2 [8\%] patients could do only selected jobs and only one [4\%] patient had shown her inability to perform any of the work. At final follow-up only four patients lacked more than $10^{\circ}$ of dorsiflexion.

At the final follow up all fractures were healed radiologically, $23(92 \%)$ patients showed anatomical reduction and maintenance of reduction and fixation at final follow-up. Only $2(8 \%)$ patients had mild reactive changes at the joint margins.

As per Baird and Jackson ${ }^{5}$ scoring system, Fair and poor results were found in 21 [84\%] and 4 [16\%] patients respectively in this series.

Complications were divided into Major (Deep infections or Osteomyelitis, Loss of reduction and fixation) and Minor (Superficial infections, wound sloughs, superficial skin dehiscence and stitch abscess)

\section{Case 1: FAIR Result}

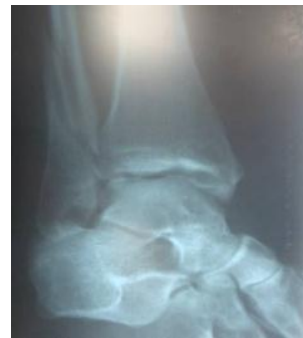

Pre-op Radiographs
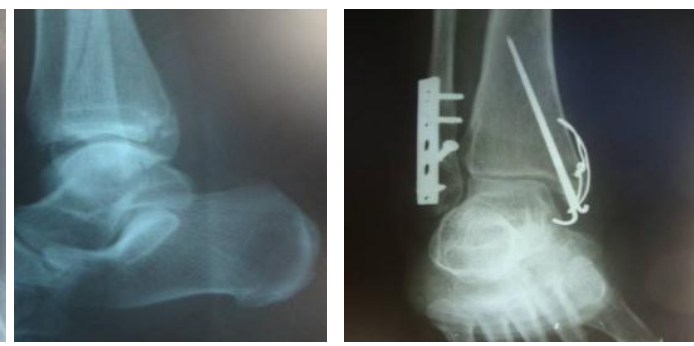

post-op radiographs at 60 weeks follow up
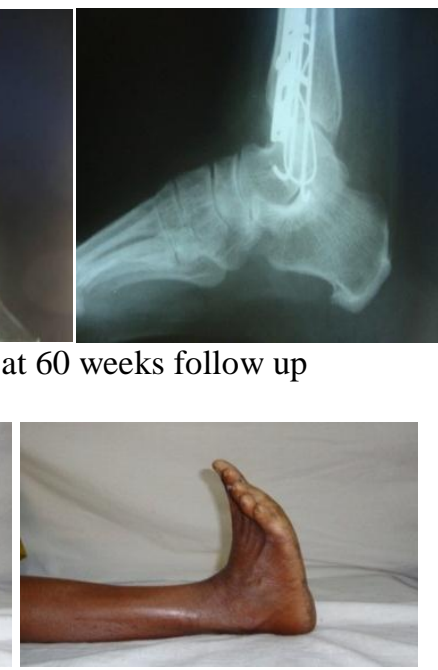

Plantar Flexion

Dorsiflexion

Neutral

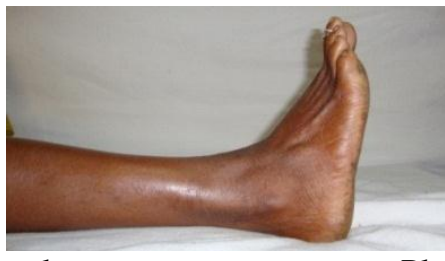

\section{Case 2: Poor Result}

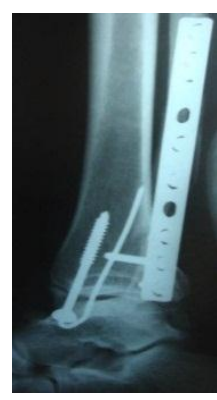

Pre-op radiographs
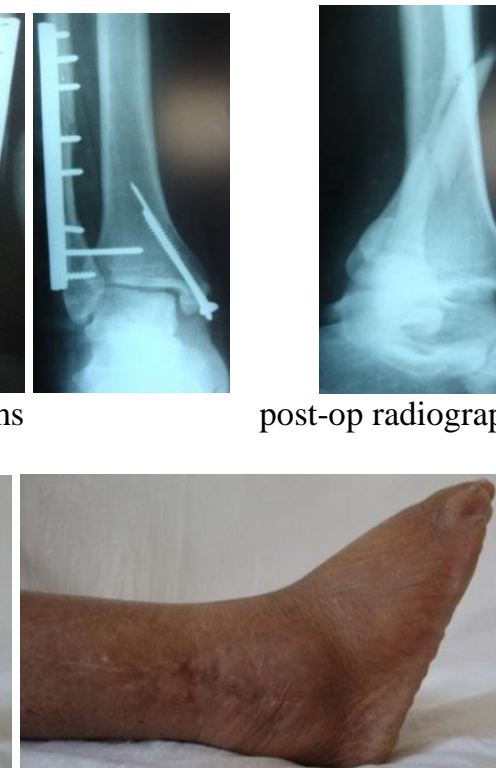

Plantar Flexion
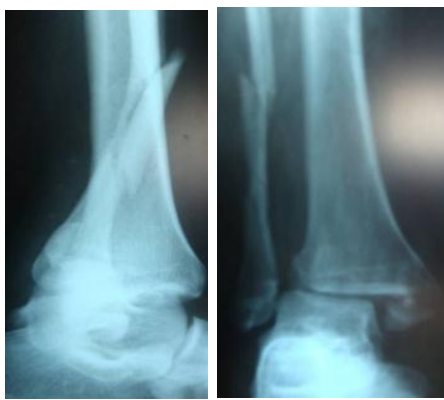

post-op radiographs at 60 weeks follow up

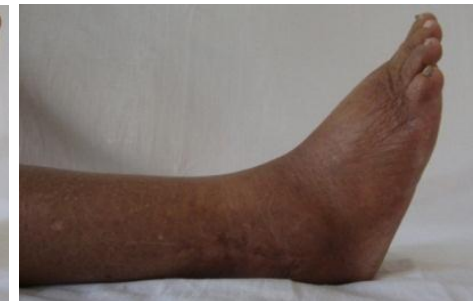

Dorsiflexion 


\section{Discussion}

Increased knowledge about the normal and post traumatic anatomy and function of the ankle joint has led to demands for exact reduction and rigid fixation of the ankle fractures. The displaced ankle fractures necessitates prompt operative treatment to ensure good functional outcome and decreased morbidity.

The treatment of malleolar fractures with accurate open reduction and stable internal fixation using $\mathrm{AO}$ method and principle was found to give a high percentage of excellent and good results. ${ }^{6}$

Mean age of patients in our study was 40.92 years (range 18 to 65 years). This finding was similar to Roberts RS $^{7}$ (40), Beris et al. ${ }^{6}$ (43), but in Baird and Jackson $^{5}$ study the average age was found to be 30 years.

There was male preponderance in this series with 16 [64\%] males and 9 [36\%] were females. Where as in Roberts et al and Beri et al there was female preponderance.

Lauge-Hansens classification system was used to classify the injuries in the present study. The most common type of injury was Supination External Rotation and least common was Pronation Abduction. This finding was similar to observation with Baird and Jackson $^{5}$, Beris et $\mathrm{al}^{6}$ and Roberts SR. ${ }^{7}$

Burnwell \& charnley, ${ }^{7}$ Baird and Jackson ${ }^{5}$, Beris et $\mathrm{al}^{6}$ and Roberts $\mathrm{RS}^{7}$ achieved more than $75 \%$ of good to excellent results in their studies. Where as In our study at final follow up, we obtained 21 fair results as per Baird and Jackson ${ }^{5}$ scoring system and none in the good to excellent, most probably because we limited our follow up period for 60 weeks only and no patient was allowed to run in that period. In all other studies the follow up period varied between 5 to 12 years and all patients running ability was evaluated at final follow up.

The ankle joint is subject to enormous forces across a relatively small surface area of contact, with up to 1.5 times body weight with gait and greater than 5.5 times body weight with more strenuous activity. Maintaining congruency of the ankle joint is therefore critical to the long term viability of the ankle. Decreased surface contact area leads to an abnormal distribution of joint stresses, which leads to post traumatic arthritis. Thordarson and colleagues ${ }^{8}$ showed that $2 \mathrm{~mm}$ of shortening or lateral shift of fibula or external rotation greater than or equal to $5^{0}$ increases contact forces in the ankle joint, which may predispose to ankle arthritis.

In our study, after surgery, only 2 patients had superior joint space of more than $2 \mathrm{~mm}$ and talar tilt more than $2 \mathrm{~mm}$. The cause of the inadequate reduction in these two patients is due to excessive comminution and poor bone quality.

Observation in this study support the contention of Yablon et $\mathrm{al}^{9}$ that lateral malleolus is key to anatomical reduction of the malleolar fractures, because the displacement of the talus faithfully followed that of the lateral malleolus. Poor reduction of distal part of fibula would result in persistent lateral displacement or residual shortening. This does not necessarily lessen the importance of the medial malleolus in contributing to the congruity of the medial aspect of the ankle, but it does serves to emphasize that the lateral malleolus should no longer be ignored in the treatment of ankle injuries.

The size of the posterior malleolar fragment plays a significant role in the post traumatic arthritis, with large fragment (those involving area more than $25 \%$ of the tibial articular surface) having poorer outcomes. The present study had three patients with posterior malleolar fracture (size less than 25\% of the tibial articular surface), none of these patients were treated by fixing the posterior malleolus and at the final follow up 2 patients showed good results and one patient had poor result.

A number of different post-operative protocols are in practice. Burnwell and Charnley ${ }^{7}$ series followed joint mobility exercises in bed until motion was restored followed by full weight bearing in a cast. Lund-Kristensen et $\mathrm{al}^{10}$ either used no cast or applied one for a few days postoperatively and then allowed full joint mobilization out of the cast. Crutches were used to maintain a non-weight bearing status. Meyer and Kumler ${ }^{11}$ series had a post- operative cast but only for an average of 3.8 weeks followed by non-weight bearing mobilization until fracture union. Whereas in our series a below knee POP cast was applied with a dorsal window, to facilitate passive dorsiflexion movement of the foot. Non Weight- bearing mobilization was allowed for 4 weeks. After 4 weeks, cast was discontinued and active range of motion was started with partial weight bearing. Full weight bearing was allowed after 12 weeks.

Our study suggests that a ruptured deltoid ligament can be left unexplored, thereby reducing the soft tissue manipulation and surgery time all ankle fractures after fixation treated by early mobilization and gradually increased weight bearing. Protected mobilization in slab or cast with dorsal window for 6 weeks allows soft tissues to heal adequately. In our study only one patient had clinical instability at final follow-up.

\section{Conclusion}

Malleolar fractures of ankle have a varied presentation. They can range from isolated fibular fractures with no displacement to a trimalleolar fracture with dislocation and vascular compromise. A broad understanding of all aspects of mechanism of injury, pathoanatomy and treatment options coupled with training experience is required before any attempt should be made to treat these injuries. With thorough understanding of injury patterns, repair of the damaged ankle joint can lead to rewarding outcomes for the patient and physician. 
We conclude that anatomical reduction is essential in all malleolar fractures of ankle as it is a weight bearing joint. Open reduction and internal fixation guaranty high standard of reduction besides eliminating the chances of loss of reduction. Restoration of fibular length and rotation is critical in re-establishing a stable ankle mortise and perfect talar alignment. Tension band wiring is the preferred method for small fracture fragments and osteoporotic bones of both medial and lateral malleolus.

Application of plaster slab and cast for 6 weeks allows the soft tissues around the ankle to heal adequately, thereby reducing clinical instability. And dorsal window facilitates the early passive mobilisation of the ankle, preventing ankle stiffness postoperatively.

Perfect Anatomical reduction and good internal fixation, post-operative ankle mobilization is directly proportional to the final result.

\section{References}

1. Court-Brown, C.M., McBirnie, J. and Wilson, G. (1998) Adult Ankle Fractures-An Increasing Problem? Acta Orthopaedica Scandinavica, 69, 43-47. http://dx.doi.org/10.3109/17453679809002355.

2. Daly, P.J., Fitzgerald Jr., R.H., Melton, L.J, and Ilstrup, D.M. (1987) Epidemiology of Ankle Fractures in Rochester, Minnesota. Acta Orthopaedica Scandinavica, 58, 539-544. http://dx.doi.org/10.3109/17453678709146395.

3. Jensen, S.L., Andresen, B.K., Mencke, S. and Nielsen, P.T. (1998) Epidemiology of Ankle Fractures: A Prospective Population-Based Study of 212 Cases in Aalborg, Denmark. Acta Orthopaedica Scandinavica, 69, 48-50. http://dx.doi.org/10.3109/17453679809002356.

4. Donken, C.C.M.A., Al-Khateeb, H., Verhofstad, M.H.J. and van Laarhoven, C.J.H.M. (2012) Surgical versus Conservative Interventions for Treating Ankle Fractures in Adults. The Cochrane Database of Systematic Reviews, Published Online. http://dx.doi.org/10.1002/14651858.CD008470.

5. Fracture of the distal part of fibula with associated disruption of deltoid ligament. Baird RA and Jackson ST; JBJS, 1987; 69A:1346-52.

6. Surgical treatment of malleolar fractures-a review of 144 patients. Beris AE, Kabbani KT, Xenakis TA, Mitsionis G, Soucacos PN. Clinical Orthopaedic Related Research, 1997 Aug;341:90-98.

7. The treatment of displaced fractures at the ankle by rigid internal fixation and early joint movement. Burnwell HD \&Charnley AD; JBJS, 1965;47 B;643-660.

8. Thordarson DB, Motamed S, Hedman T, Ebramzadeh E, Bakshian S. The effect of fibular malreduction on contact pressures in an ankle fracture malunion model. J Bone Joint Surg Am 1997;79:1809-1815.

9. The key role of the lateral malleolus in displaced fractures of ankle. Yablon IG, Heller FG, Shouse L. JBJS, 1977;57A: 169-173.

10. Lundberg A, Goldie I, Kalin B, Selvik G. Kinematics of the ankle/foot complex: Plantar flexion and dorsiflexion foot and ankle. 1989;9:194-200.

11. Meyer TL, Kumler KN. ASIF technique and ankle fractures, Clin Orthop, 1980;150:211-216. 